\title{
Secure Transportation Management
}

\author{
Philip Gibbs \\ Brookhaven National Laboratory
}

October 2014

Nonproliferation and National Security Department Brookhaven National Laboratory

U.S. Department of Energy

National Nuclear Security Administration Office of International Material Protection and Cooperation

BNL-106286-2014-IR

Notice: This manuscript has been authored by employees of

Brookhaven Science Associates, LLC under Contract No. DE-AC02$98 \mathrm{CH} 10886$ with the U.S. Department of Energy. The publisher by accepting the manuscript for publication acknowledges that the United States Government retains a non-exclusive, paid-up, irrevocable, world-wide license to publish or reproduce the published form of this manuscript, or allow others to do so, for United States Government purposes.

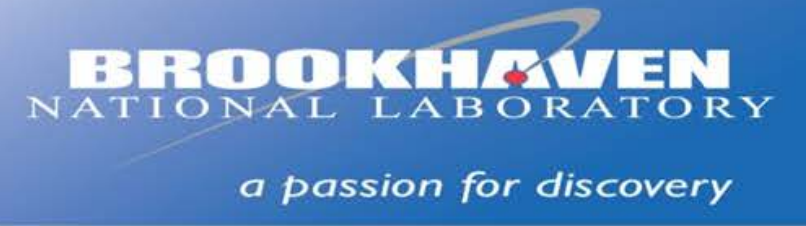

(6) ENEReY $\mid \begin{aligned} & \text { omice of } \\ & \text { scionoe }\end{aligned}$ 


\section{SCLAI MER}

This report was prepared as an account of work sponsored by an agency of the United States Government. Neither the United States Government nor any agency thereof, nor any of their employees, nor any of their contractors, subcontractors, or their employees, makes any warranty, express or implied, or assumes any legal liability or responsibility for the accuracy, completeness, or any third party's use or the results of such use of any information, apparatus, product, or process disclosed, or represents that its use would not infringe privately owned rights. Reference herein to any specific commercial product, process, or service by trade name, trademark, manufacturer, or otherwise, does not necessarily constitute or imply its endorsement, recommendation, or favoring by the United States Government or any agency thereof or its contractors or subcontractors. The views and opinions of authors expressed herein do not necessarily state or reflect those of the United States Government or any agency thereof. 


\section{MVS NAS \\ Secure Transportation Management}

Workshop Overview

October 2014 


\section{Course I nformation}

Course Title

- Secure Transportation Management Course (STMC)

Course Length

Option 1 - 5 days

Option 2 - 11 days (additional exercises)

Week 1 - Mon - Sat

Week 2 - Mon - Fri 


\section{Mission and Purpose}

The STMC course provides managers with information related to procedures and equipment used to successfully transport special nuclear material. The information presented is reinforced through the use of numerous practical exercises.

Each practical exercise is a building block for the next exercise, designed to defend against the identified threat. 


\section{Mission and Purpose (continued)}

Following the final lesson there will be three practical convoy exercises. These exercises consist of three different routes, conducted over three days.

Note: Only in 2 week version 


\section{Scope}

The course focuses on the following topical areas from a managers perspective:

- Understanding the regulatory framework for secure transportation of special nuclear materials

- Identifying the insider and outsider threat(s) to secure transportation 


\section{Scope (continued)}

- Organization of a secure transportation unit

- Management and supervision of secure transportation units

- Equipment and facilities required

- Training and qualification needed 


\section{Scope (continued)}

- Communications on a national, convoy, and individual level

- Documentation of practical exercises

- Vulnerability assessments of secure transportation units/convoys

- Conduct of convoy operations

- Three practical exercises in convoy operations 


\section{Lesson 1: Regulatory Framework}

Goal:

- A working level knowledge of the secure transportation nuclear regulatory framework.

Objectives:

- Discuss the regulations that govern the security and transportation of nuclear material.

- Discuss the organizational alignment for those responsible for nuclear transport. 


\section{Lesson 2: Threats to Nuclear Materials in Transport}

Goal:

- A working level knowledge of the threats to nuclear materials convoys and facilities and the impact these threats have on transportation security operations.

Objectives:

- Discuss the purpose of a Design Basis Threat. 


\section{Lesson 2: Threats to Nuclear Materials in Transport (continued)}

Objectives: (continued)

- Discuss the three questions that any good threat definition should answer.

- Discuss the types of adversaries which may threaten a nuclear material convoy or facility.

- Discuss tactics employed by adversaries.

- Discuss the capabilities of potential adversaries. 


\section{Lesson 2: Threats to Nuclear Materials in Transport (continued)}

\section{Practical Exercise:}

- Threat Identification Exercise

- Provide an awareness of the threats that convoys may face, and to provide practical experience developing threat tables. 


\section{Lesson 3: Organization of a Secure Transportation Unit}

Goal:

- A working level knowledge of how to organize a secure transportation unit.

Objectives:

- Discuss the organization created to provide safe and secure transportation of nuclear weapons, nuclear weapon components, and special nuclear material (SNM). 


\section{Lesson 3: Organization of a Secure Transportation Unit (continued)}

Practical Exercise:

- Secure Transportation Organizational Structure Exercise

- Design and discuss the organizational structure of a secure transportation unit. 


\section{Lesson 4: Management and Supervision}

Goal:

- A working level knowledge of hiring and retention practices, and the management and supervision structure as related to secure transportation personnel.

Objectives:

- Discuss the selection process to ensure quality candidates 
Lesson 4: Management and Supervision (continued)

Objectives: (continued)

- Discuss candidate entry level training

- Discuss using a systematic approach to training to achieve performance based metrics

- Discuss the management and supervision organizational structure 
Lesson 4: Management and Supervision (continued)

Practical Exercise

- Secure Transportation Protective Force Type and Size

- Determine the required size and makeup of a secure transportation protective force necessary to guard a materials transport. 


\section{Lesson 5: Equipment and Facilities}

Goal:

- A working level knowledge of the equipment and facilities needed to support convoy operations

Objectives:

- Discuss vehicles needed for convoy operations

- Discuss the equipment each agent needs for convoy operations

- Discuss the facilities needed to support convoy operations 


\section{Lesson 5: Equipment and Facilities}

(continued)

\section{Practical Exercise:}

- Equipment Needs Exercise

- Determine the equipment required to support a secure transportation unit. 


\section{Lesson 6: Training and Qualifications}

Goal:

- A working level knowledge of the importance of training and qualifications in an effective and efficient secure transportation operation

Objectives:

- Discuss the requirements for training and qualification programs 


\section{Lesson 6: Training and Qualifications}

(continued)

Objectives:

- Discuss the importance of a systematic performance-based training process

- Discuss required instructor qualifications

- Discuss the types of training required

- Practical Exercise: Training Requirements

- Determine the training required to support a secure transportation unit. 


\section{Lesson 7: Communications}

Goal:

- A working level knowledge of convoy operation communication needs.

Objectives:

- Discuss the types of communications needed to track a convoy 


\section{Lesson 7: Communications (continued)}

Objectives:

- Discuss communications between the communication center and each convoy

- Discuss vehicle to vehicle communications

- Discuss individual portable communications

- Discuss radio communication procedures 


\section{Lesson 7: Communications (continued)}

\section{Practical Exercise:}

- Tactical Communications

- Introduce the concept of tactical communications. 


\section{Lesson 8: Documentation}

Goal:

- A working level knowledge of plans and orders and the purpose of a Transportation Security Plan

Objectives:

- Discuss characteristic of good plans and orders

- Discuss types of plans and orders 


\section{Lesson 8: Documentation (Continued)}

Objectives:

- Discuss requirements for well documented plans and orders

- Discuss the purpose and application of a Transportation Security Plan

- Practical Exercise: Transportation Security Plan

- Write a Transportation Security Plan using the IAEA format. 
Lesson 9: Vulnerability Assessments on Secure Transportation

Goal:

- A working level knowledge of vulnerability analysis techniques as applied to Secure Transportation Management

Objective:

- Discuss the VA process and the specific tool used in this course (VISA) 
Lesson 9: Vulnerability Assessments on Secure Transportation (continued)

Objectives:

- Conduct practical exercises using identified theft scenarios and the VISA tool to define various levels of conditional risk for each scenario

- Conduct a characterization of a notional road convoy focusing on physical security elements 


\section{Lesson 9: Vulnerability Assessments on Secure Transportation (continued)}

\section{Practical Exercises:}

- 1) Transportation Security Pre-Convoy Operations;

2) Adversary Timeline; 3) Table Top Exercise Documentation Report; 4) Short Convoy

- Provide an awareness of the process associated with performing a transportation vulnerability analysis and to provide practical experience developing check lists, timelines and analysis matrixes. 


\section{Lesson 10: Convoy Operations (2 week version only)}

Goal

- A working level knowledgeable of convoy operations Objectives

- Discuss the transportation element under normal operations 


\section{Lesson 10: Convoy Operations (continued)}

Objectives

- Discuss the response element under normal operations

- Discuss convoy and vehicle assignments

- Discuss convoy departure and arrival times

- Discuss the pre-trip briefings 


\section{Lesson 10: Convoy Operations (continued)}

Objectives

- Discuss the convoy activities during stops

- Discuss interaction with outside agencies

- Discuss accepting and releasing cargo responsibilities

- Discuss destination arrival activities

- Discuss convoy reactions to an attack 


\section{Lesson 10: Convoy Operations (continued)}

\section{Practical Exercises}

- Convoy Operations

- Provide the opportunity to observe and participate in simulated convoy operations. 